\title{
Special Approach to Detecting Incipient Fault in Power Transformer Using Dissolved Gas Analysis
}

\author{
Makwana Mehulkumar B ${ }^{1}$, Ankit Shahpatel ${ }^{2}$ \\ G.H.Patel College of Engineering and Technology VVNagar, India ${ }^{1,2}$
}

\begin{abstract}
Transformer insulation aging diagnosis is important for all the condition assessment Dissolved gas analysis (DGA) is one of the most useful techniques and tools to detect the incipient faults in large oil filled transformers. DGA is most useful condition monitoring technique as primary diagnosis method for detecting incipient fault in oil filled transformer in this paper I have use MATLAB programing to detecting present transformer condition according to Dissolved gases in transformer oil as per IEC and IEEE Gas ratio code. It also describes the structure and specific features of transformer insulation ageing diagnosis based IEC codes and Rogers's ratio method. MATLAB programs using this two methods were developed to automate. Also this paper present three fault type, partial discharges (PD), arc discharges, and thermal faults, Winding circulate current.
\end{abstract}

Keywords: acetylene ( $\mathrm{C} 2 \mathrm{H} 2)$, carbon monoxide $(\mathrm{CO})$, carbon dioxide (CO2), Dissolved gas analysis (DGA), ethylene $(\mathrm{C} 2 \mathrm{H} 4)$, ethane (C2H6), Key gases, hydrogen $(\mathrm{H} 2)$, methane (CH4),

\section{INTRODUCTION}

Transformer is static electromagnetic device. From the day of this equipment in service, Different stresses like electrical, mechanical, chemical and environmental effect the condition of the transformer. At the initial stages, Degradation of insulation quality occurs slowly. But this deterioration multiplies in due course of time and leads to final failure of the transformer. So, to overcome this situation, continuous monitoring of the condition and preventive measures is required for correct maintenance of the transformer. This can be achieved by providing the condition monitoring of Transformer to be done at earlier Stages via online or through offline.

As a major apparatus in a power system, the power transformer is vital to system operation. Techniques for Diagnosis and incipient-fault detection are valuable. A transformer is subject to electrical and thermal stresses which could break down the inculcating materials and release gaseous decomposition products.

Condition monitoring of any transformer can only be successful if it is possible to have an early fault detection. The dissolved gas analysis (DGA) of transformers can provide an insight view related to thermal and electrical stresses during operations of oil immersed power transformers. DGA is accustomed to detect elementary faults in the transformer. It is found that the abrupt changes in concentration and ratio of various gases interpret the health of transformer. So to improve the transformer health it is required to continuously monitor all the gases. Gases are necessary to be monitored at every instant as every gas contribute either in some parameter or will be the reason of rise of any other gas. The two stresses could break down insulation materials and release gaseous decomposition products.

Overheating, corona and arcing are three primary causes of fault related gases. Principally, the fault related gases commonly used are hydrogen (H2), carbon monoxide $(\mathrm{CO})$, carbon dioxide $(\mathrm{CO}$,$) , methane (\mathrm{CH} 4)$, acetylene $(\mathrm{C} 2 \mathrm{H} 2)$, ethane $(\mathrm{C} 2 \mathrm{H} 6)$, and ethylene $(\mathrm{C} 2 \mathrm{H} 4)$.

The analysis of dissolved gases is a powerful tool to diagnose developing faults in power transformers. Early detection of faults is very important for saving transformer from any catastrophic failure so condition Monitoring of Transformer must be Required for early Detection of fault and take the necessary preventive action to avoid the total failure of transformer.

\section{DISSOLVED GAS ANALYSIS}

DGA is a diagnostic techniques for detecting and evaluating of incipient faults in oil immersed transformers. A fault is causes abnormal dissipation of energy within the transformer. When a fault occurs in the transformer, the insulation system will undergo chemical degradation which leads to a production of various gases that dissolves in the oil. These gases are often referred to as key gases, and from their concentrations we can identify different types of fault occurring in the transformer.

Analysis Dissolved gases-in-oil analysis (DGA) is most useful technique in transformer fault diagnosis. Electrical insulation such as mineral oils and cellulosic materials degrade under excessive thermal and electrical stresses, forming byproduct gases which can serve as indicators of the type of stress and its severity. Dissolved gas-in-oil concentrations, relative proportion of gases, and gas generation rates (gassing rates) are used to estimate the condition of a transformer.

Commonly used gases include hydrogen (H2), methane $(\mathrm{CH} 4)$, acetylene $(\mathrm{C} 2 \mathrm{H} 2)$ ethylene $(\mathrm{C} 2 \mathrm{H} 4)$, ethane (C2H6), carbon monoxide (CO), and carbon dioxide $(\mathrm{CO} 2)$. These gases are extracted from the oil under high 
vacuum and analyzed by Gas Chromatograph to get each gas concentration separately.

\section{PROCEDURE OF DGA}

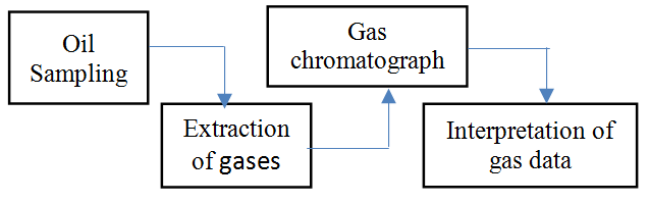

Methods for Interpretation of Gas data:

The standards IEC [4] and IEEE [5] provide guidelines for interpretation of DGA. In these standards one can for example find graphical interpretations of gas ratios and numerical tables for typical gas concentrations within oil immersed transformer in operation.

\section{IEC Ratio code:}

\begin{tabular}{|c|c|c|}
\hline \multirow{2}{*}{$\begin{array}{c}\text { Gas } \\
\text { Ratios }\end{array}$} & $\begin{array}{c}\text { Range of gas } \\
\text { ratio code }\end{array}$ & $\begin{array}{c}\text { Range of } \\
\text { code } / \text { IEC } \\
\text { code }\end{array}$ \\
\hline \multirow{4}{*}{$\mathrm{C}_{2} \mathrm{H}_{2}$} & $<0.1$ & 0 \\
\cline { 2 - 3 } & $0.1-1.0$ & 1 \\
\cline { 2 - 3 } $\mathrm{C}_{2} \mathrm{H}_{4}$ & $1.0-3.0$ & 1 \\
\cline { 2 - 3 } & $>3.0$ & 2 \\
\hline \multirow{3}{*}{$\mathrm{CH}_{4}$} & $<0.1$ & 1 \\
\cline { 2 - 3 } & $0.1-1.0$ & 0 \\
\cline { 2 - 3 } $\mathrm{H}_{2}$ & $1.0-3.0$ & 2 \\
\hline \multirow{3}{*}{$\mathrm{C}_{2} \mathrm{H}_{4}$} & $>3.0$ & 2 \\
\cline { 2 - 3 } & $<0.1$ & 0 \\
\cline { 2 - 3 } $\mathrm{C}_{2} \mathrm{H}_{6}$ & $0.1-1.0$ & 1 \\
\cline { 2 - 3 } & $1.0-3.0$ & 2 \\
\hline
\end{tabular}

Table I: IEC Ratio code

The ratios of the different gases and its range according to calculate value of ratio the following table give the codes according to gas concentration. And from this codes combination we can classified which types of fault presence in transformer.

Fault Classification according to IEC Codes: The following table shows the combination of codes and according to this codes it classify the type of fault indicate by transformer oil

\begin{tabular}{|c|c|c|l|}
\hline$\frac{\mathrm{C}_{2} \mathrm{H}_{2}}{\mathrm{C}_{2} \mathrm{H}_{4}}$ & $\frac{\mathrm{CH}_{4}}{\mathrm{H}_{2}}$ & $\frac{\mathrm{C}_{2} \mathrm{H}_{4}}{\mathrm{C}_{2} \mathrm{H}_{6}}$ & \multicolumn{1}{|c|}{ FAULT TYPE } \\
\hline 0 & 0 & 2 & Partial discharge of low energy \\
\hline 0 & 1 & 1 & Thermal Fault of low temperature $150-300^{\circ} \mathrm{C}$ \\
\hline 0 & 1 & 2 & Thermal Fault of low temperature $450^{\circ} \mathrm{C}$ \\
\hline 1 & 0 & 0 & Flashover, Intermittent sparking \\
\hline 1 & 1 & 1 & Thermal Fault of low temperature $150-300^{\circ} \mathrm{C}$ \\
\hline 1 & 1 & 2 & Thermal Fault of high temperatures $>700^{\circ} \mathrm{C}$ \\
\hline 1 & 2 & 0 & Core and tank circulating currents. \\
\hline 1 & 2 & 1 & Winding Circulating currents. \\
\hline 1 & 2 & 2 & Core and tank circulating currents. \\
\hline 2 & 0 & 0 & Partial discharge of high energy density, Corona \\
\hline 2 & 0 & 1 & Discharge of high energy, Arcing. \\
\hline 2 & 0 & 2 & Discharges of low energy, Continuous sparking \\
\hline 2 & 1 & 0 & Partial discharge of high energy density, Corona \\
\hline 2 & 1 & 1 & Discharge of high energy, Arcing. \\
\hline 2 & 1 & 2 & Discharges of low energy, Continuous sparking \\
\hline 2 & 2 & 0 & \multicolumn{2}{|c}{} \\
\hline 2 & 2 & 1 & Severe arcing, Overheating of oil $>1000^{\circ} \mathrm{C}$ \\
\hline 2 & 2 & 2 & \multicolumn{1}{|c}{} \\
\hline
\end{tabular}

Table I: Fault Classification

IF the ratio $\mathbf{C O / C O 2 > 0 . 1}$ Transformer shows High temperature then Normal in Insulation.

\section{MATLAB PROGRAMMING:}

From The Analysis of Key gases concentration in the transformer oil and its ratio according to Rogers method \& IEC code I have prepped MATLAB program for which type of fault in the transformer May occurs in future.

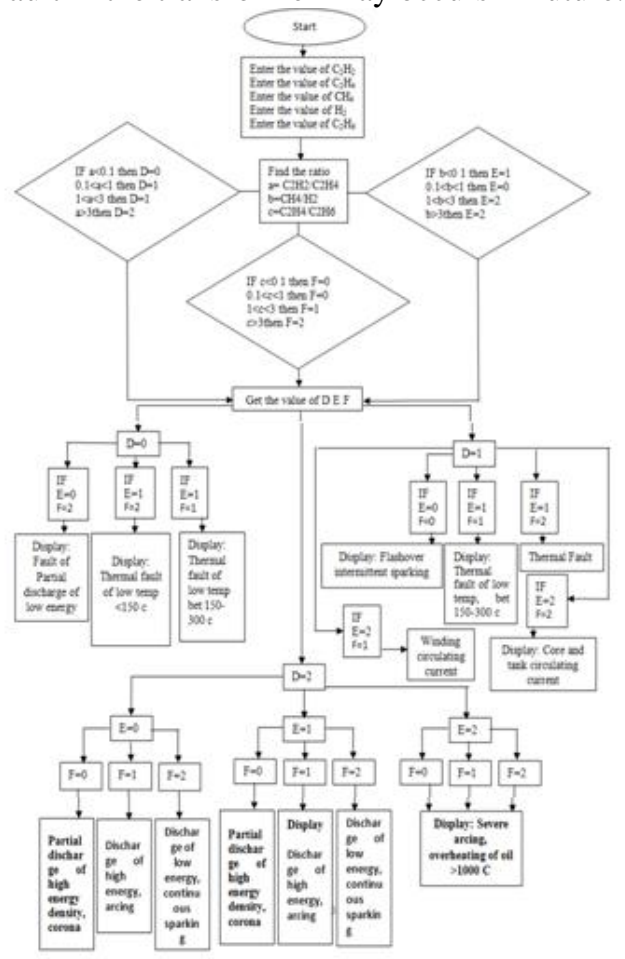

By the Entering the Value of concentration of gages in oil in MATLAB Program input we get the resultant fault according to IEC standard.

\section{CASE STUDT ON DGA}

Rating of Transformer: 15 MVA 220/66/

MAKE: ATLANTAS ELECT PVTLTD

\begin{tabular}{|c|c|c|c|c|c|c|c|c|}
\hline $\mathrm{H} 2$ & $\mathrm{O} 2$ & $\mathrm{~N} 2$ & $\mathrm{CH} 4$ & $\mathrm{C} 2 \mathrm{H} 2$ & $\mathrm{C} 2 \mathrm{H} 4$ & $\mathrm{C} 2 \mathrm{H} 6$ & $\mathrm{CO}$ & $\mathrm{CO} 2$ \\
\hline 1708 & 3635 & 12513 & 4 & 0 & 29 & 4 & 17 & 159 \\
\hline
\end{tabular}

Sample take: Bottom point

TABLE III: Gas level in PPM

Result: Thermal fault of low temperature between 150$300 \mathrm{deg}$ c $\mathrm{CO} / \mathrm{CO} 2=0.1069$, Sows insulation overheating DGA indicates Hydrogen \& Hydrocarbons So need to Investigate the fault \& Resample after investigation.

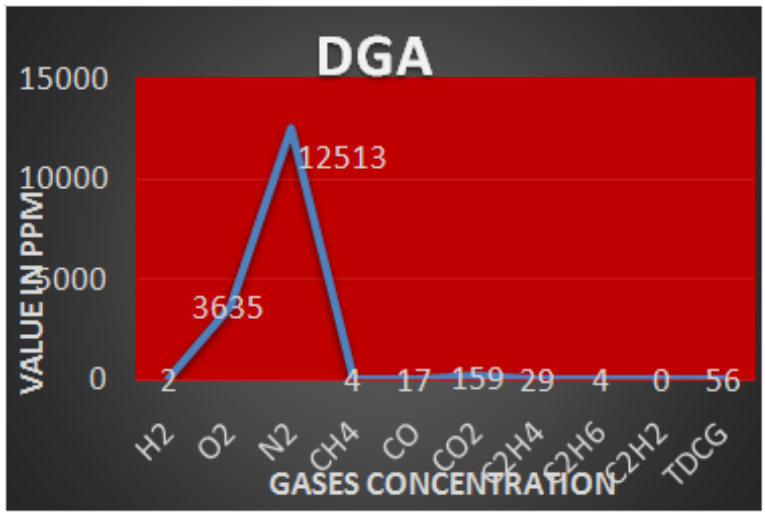

FIG 1. Gas concentration at faulty condition 


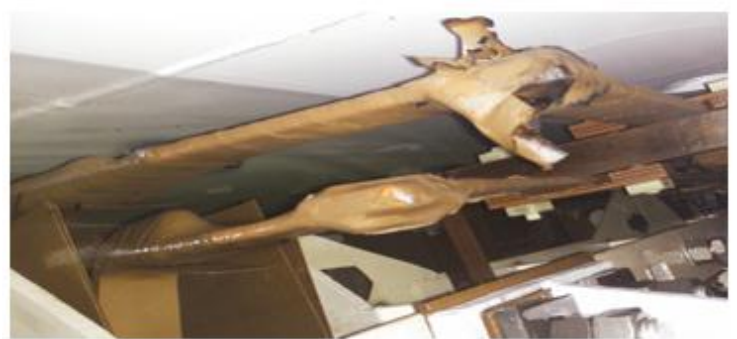

FIG 2. LV-U phase Bus bar bolted joint found affected

Gas concentration after maintaining transformer:
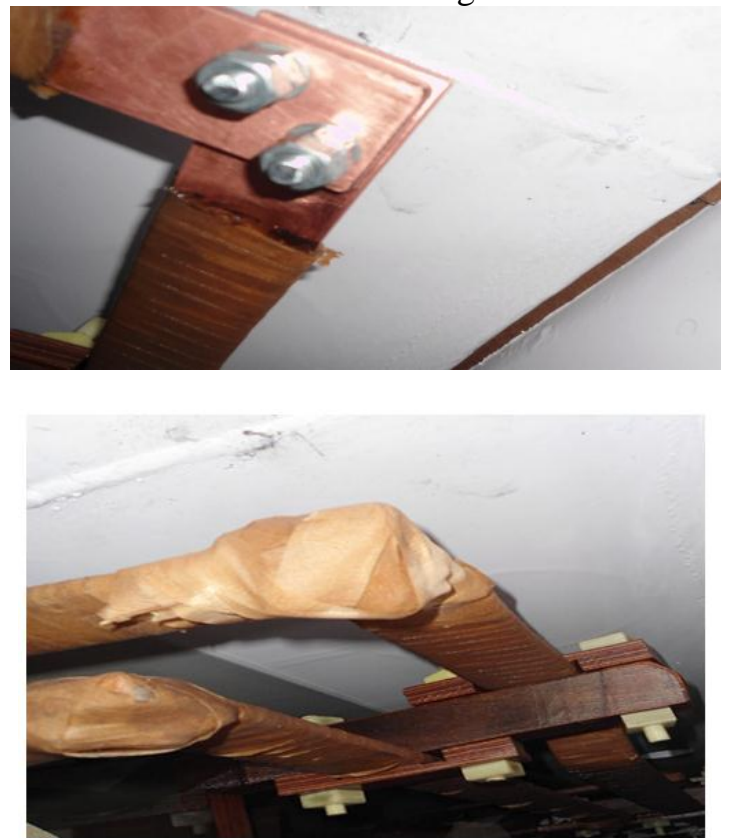

FIG 3.Paper covering and rejoining bolt

\begin{tabular}{|c|c|c|c|c|c|c|c|c|}
\hline $\mathrm{H} 2$ & $\mathrm{O} 2$ & $\mathrm{~N} 2$ & $\mathrm{CH} 4$ & $\mathrm{C} 2 \mathrm{H} 2$ & $\mathrm{C} 2 \mathrm{H} 4$ & $\mathrm{C} 2 \mathrm{H} 6$ & $\mathrm{CO}$ & $\mathrm{CO} 2$ \\
\hline 0 & 3185 & 10357 & 0 & 0 & 0 & 0 & 6 & 150 \\
\hline
\end{tabular}

TABLE IV: Gas level in PPM

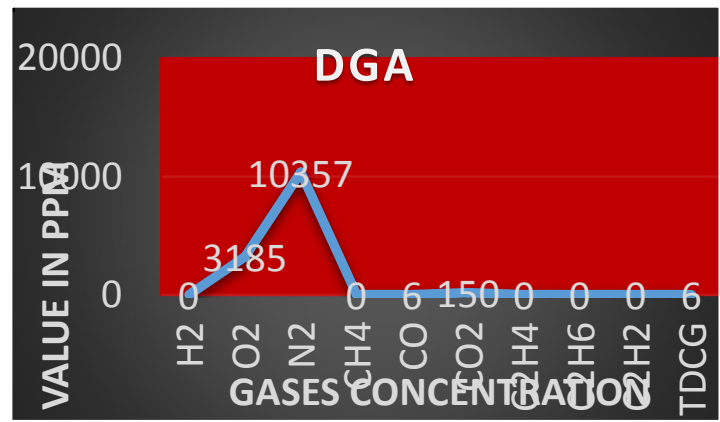

FIG 4.Gas concentration after maintaining transformer

\section{CONCLUSION}

Analyzing insulating oil taken from transformers is a primary way of identifying problems occurring within a transformer. By identifying and quantifying the gases found in transformer oil, the condition of the transformer can be monitored. If faults are found to be occurring, outages can be planned and the fault can be rectified before major damage can occur. The in Samples should be taken regularly and records kept.

\section{REFERENCES}

[1]. Er.S.Sehgal and Er.D.singh, "Dissolve gas analysis", IJERT Vol. 1 Issue 6, August - 2012.

[2]. R.pandey, MT.Deshpande, "Dissolved Gas Analysis of Mineral Oil Used in Transformer" IJAIEM Volume 1, Issue 2, October2012.

[3]. SY.Jasmin and J.Shreevastava, "Dissolve gas Analysis of Power transformer", IJEEER Vol. 3, Issue 5, Dec 2013, 1-10.

[4]. IEC Standards 60599, "Mineral oil-impregnated electrical equipment in service" - Guide to the interpretation of dissolved and free gases analysis, second edition, March 1999

[5]. IEEE Standards C57.104-1991. IEEE Guide for the Interpretation of gases generated in Oil-Immersed Transformers, 1991.

[6]. DeepikaBhalla, RK Bansal, and HariOm Gupta, "Application of Artificial Intelligence Technique for DGA of Transformers-A Review", World Academy of Science, Engineering and Technology Vol; 4 2010-02-27.

[7]. Ali A. Albakry, "Modified Fault Diagnosis Method for Power Transformers Using Fuzzy Logic Technique", Journal of Babylon University / pure and applied science.

[8]. "A guide to Transformer Oil Analysis" BYI.A.R. GRAY Transformer Chemistry Services.

[9]. Sadeq Y. Jasmin and Jyoti Shrivastava "Dissolved gas analysis of power transformers", International Journal of Electrical and Electronics Engineering Research (IJEEER) ,Vol. 3, Issue 5, Dec 2013, 1-10.

[10]. Rohits Kumar Arora,"Different DGA Techniques for Monitoring of Transformers",International Journal of Electronics and Electrical Engineering Vol. 1, No. 4, December, 2013

[11]. Rogers R. R. 1978, "IEEE and IEC code to interpret incipient faults in transformers using gas in oil analysis ". IEEE transaction electrical Insulation, Vo.13, No.5, 1978 